LM-04K044

June 9, 2004

\title{
Analysis of Recombination Processes in 0.5-0.6 eV Epitaxial GalnAsSb Lattice-matched to GaSb
}

D Donetsky, S Anikeev, N Gu, G Belenky, S Luryi, CA Wang, DA Shiau, M Dashiell, J Beausang, and G Nichols

This report was prepared as an account of work sponsored by the United States Government. Neither the United States, nor the United States Department of Energy, nor any of their employees, nor any of their contractors, subcontractors, or their employees, makes any warranty, express or implied, or assumes any legal liability or responsibility for the accuracy, completeness or usefulness of any information, apparatus, product or process disclosed, or represents that its use would not infringe privately owned rights. 


\title{
Analysis of Recombination Processes in 0.5-0.6 eV Epitaxial GaInAsSb Lattice-matched to GaSb
}

\author{
D. Donetsky, S. Anikeev, N. Gu, G. Belenky, S. Luryi \\ State University of New York at Stony Brook, Stony Brook, NY 11794 \\ C. A. Wang, D.A. Shiau \\ Lincoln Laboratory, Massachusetts Institute of Technology, Lexington, MA 02420 \\ M. Dashiell, J. Beausang, G. Nichols \\ Lockheed Martin Corporation, Schenectady, NY 12301
}

\begin{abstract}
This work summarizes recent data on minority carrier lifetime in n- and p-type double heterostructures (DHs) of 0.5-0.6 eV GaInAsSb confined with GaSb and AlGaAsSb cap layers. Recombination times were measured by time-resolved photoluminescence (TRPL) and by optical frequency response (OFR) to sinusoidal excitation. It was shown that one of the mechanisms responsible for interface recombination in $\mathrm{GaSb} / \mathrm{GaInAsSb} / \mathrm{GaSb}$ DHs is thermionic emission of carriers over the heterobarrier. Considerable improvement of carrier confinement was obtained with $1 \mathrm{eV} \mathrm{AlGaAsSb}$ cap layers. Optimization of the epitaxial growth resulted in a recombination velocity at GaInAsSb/AlGaAsSb interface as low as $30 \mathrm{~cm} / \mathrm{s}$.
\end{abstract}

\section{INTRODUCTION}

Effective thermophotovoltaic (TPV) conversion of thermal radiation from emitters with temperature $\mathrm{T} \sim 1000^{\circ} \mathrm{C}$ requires semiconductor materials with bandgap of $0.5-0.6 \mathrm{eV}$ [1]. For the last decade epitaxial GaInAsSb materials lattice matched to $\mathrm{GaSb}$ have been developed for TPV application. The maximum internal quantum efficiency of $0.54 \mathrm{eV}$ GaInAsSb TPV devices approaches the theoretical limit of 100 $\%$ while the open-circuit voltage achieves only $60 \%$ of the material band gap [2]. Improvement of the device open-circuit voltage in GaSb-based devices necessitates study of carrier recombination in these materials. This paper summarizes recent data on carrier lifetime in p- and n-type epitaxial GaInAsSb.

\section{PL STRUCTURES}

Sets of isotype $\mathrm{GaSb} / \mathrm{GaInAsSb} / \mathrm{GaSb}$ and $\mathrm{AlGaAsSb} / \mathrm{GaInAsSb} / \mathrm{AlGaAsSb}$ DHs were grown by organometallic vapor phase epitaxy (OMVPE) on (100) $n$-GaSb substrates misoriented $6^{\circ}$ toward (111)B. The active layer was lattice matched to GaSb with bandgap varied in the range of $0.5-0.6 \mathrm{eV}$. The band gap of AlGaAsSb was $\sim 1$ $\mathrm{eV}$. The confinement layer thickness was $50 \mathrm{~nm}$ for $\mathrm{GaSb}$ and $20 \mathrm{~nm}$ for AlGaAsSb. It was assumed that the selected thickness of confinement layers prevents carrier tunneling. An additional 25- $\mathrm{nm}$ thick GaSb cap layer was grown on top of the upper $\mathrm{AlGaAsSb}$ layer to prevent surface oxidation. The photoluminescence (PL) spectra of 
nominally undoped GaInAsSb layers at $T=4 \mathrm{~K}$ exhibited a full width at half maximum in the range from $4 \mathrm{meV}$ for $0.6-\mathrm{eV}$ material to $10-\mathrm{meV}$ for $0.5 \mathrm{eV}$ material [3], and is indicative of high quality bulk layers.

In this work the active layer thickness was varied in the range from 0.15 to 4.5 $\mu \mathrm{m}$ in order to separate the bulk and interface recombination. $N$-type GaInAsSb DHs were Te-doped to $n=3 \times 10^{17} \mathrm{~cm}^{-3}$, and $p$-type GaInAsSb DHs were $\mathrm{Zn}$-doped to $p=$ $2 \times 10^{17} \mathrm{~cm}^{-3}$ or were nominally undoped with background hole concentration of $1 \mathrm{x}$ $10^{16} \mathrm{~cm}^{-3}$. The doping levels in PL structures were chosen to separate radiative and nonradiative recombination processes and do not necessarily represent the optimum doping concentrations in TPV devices.

\section{EXPERIMENTAL APPROACH}

Different methods were employed for contactless determination of excess carrier lifetime in narrow gap semiconductors [4-6]. Determination of the carrier lifetime from PL kinetics has a number of advantages: the measured signal is directly related to carrier concentration in the active layer, the method provides high temporal and spatial resolution, it is capable of lifetime measurements in structures with a backsurface reflector [7] and in structures with a front-surface grid contact.

Recently we developed time-resolved photoluminescence (TRPL) for lifetime measurements in mid-IR materials [8-9]. The carrier lifetime was determined from PL kinetic after short pulse excitation. The PL decay constant is known as the dynamic lifetime. The initial excess carrier concentration was kept below the background doping level to ensure a linear recombination mode. In this work, we report development of an alternative technique that determines carrier lifetime from measurement of the optical frequency response (OFR) under static excitation with small-signal sinusoidal modulation. When the period of excitation is smaller than the carrier lifetime, the intensity of the optical response decreases with increase of modulation frequency in accordance with the expression

$$
I(f) \propto \frac{1}{\sqrt{1+(2 \pi \tilde{\tau} \tau)^{2}}}
$$

Here $\tau$ is the static recombination lifetime and $f$ is the modulation frequency. The 3-dB point of PL modulation response $\left(f_{-3 d B}\right)$ determines the carrier lifetime as $\tau=1 / 2 \pi f-3 \mathrm{~dB}$. For simple recombination mechanisms, both TRPL and optical frequency response techniques yield identical results. In the static method use of a selective amplifier with narrow frequency band improves the signal-to-noise ratio. Thus, the optical response can be measured at lower excitation levels, which is important for lifetime measurements in undoped structures. Figure 1 shows a schematic of the experimental setup for optical response measurements. The excitation source was an AC-modulated laser diode operating at $\lambda=1.3 \mu \mathrm{m}$. The modulation response was measured with a spectrum analyzer in a $300-\mathrm{Hz}$ bandwidth or with a lock-in-amplifier. 


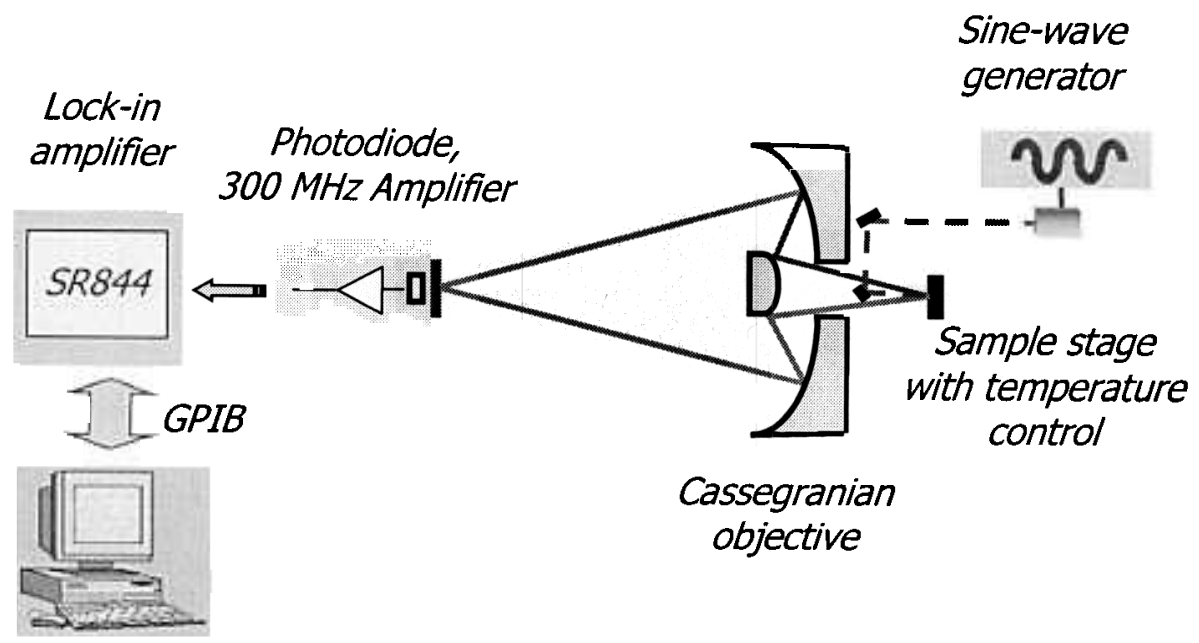

FIGURE 1. Schematic of the experimental setup for optical modulation response measurements.

In this work both dynamic and static approaches were exploited. Typical responses are shown in Figure 2. Figure 2a presents optical responses measured for two $4.5-\mu \mathrm{m}$-thick $0.54-\mathrm{eV}$ GaInAsSb DHs with hole concentration of $2 \times 10^{17} \mathrm{~cm}^{-3}$ or $1 \times 10^{16} \mathrm{~cm}^{-3}$. The cut-off frequency of $1.6 \mathrm{MHz}$ for the structure with $p=2 \times 10^{17} \mathrm{~cm}^{-}$ ${ }^{3}$ corresponds to a $100 \mathrm{~ns}$ electron lifetime. The lifetime value was obtained by fit of the OFR to expression (1). The same result for this structure was obtained by TRPL method (Figure 2b). Measurement of the optical response for the 4.5- $\mu \mathrm{m}$-thick structure with $p=1 \times 10^{16} \mathrm{~cm}^{-3}$ showed the lower bound for the bulk electron lifetime of $460 \mathrm{~ns}$. For that background carrier concentration the TRPL method was not able to guarantee the linear recombination mode. In the OFR method the excess carrier concentration for both doped and undoped structures is estimated to be $10^{15} \mathrm{~cm}^{-3}$.

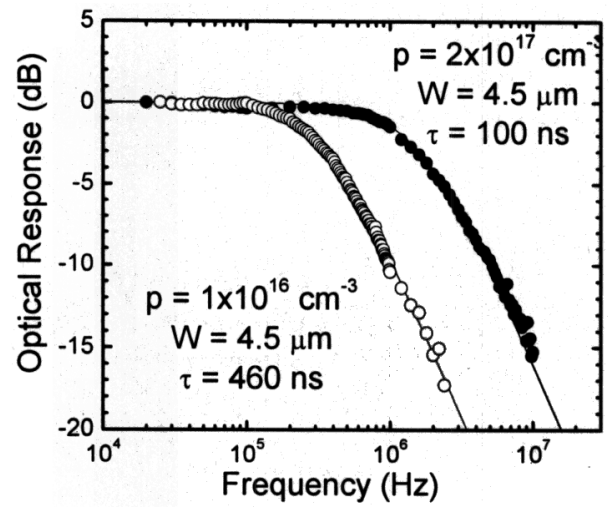

(a)

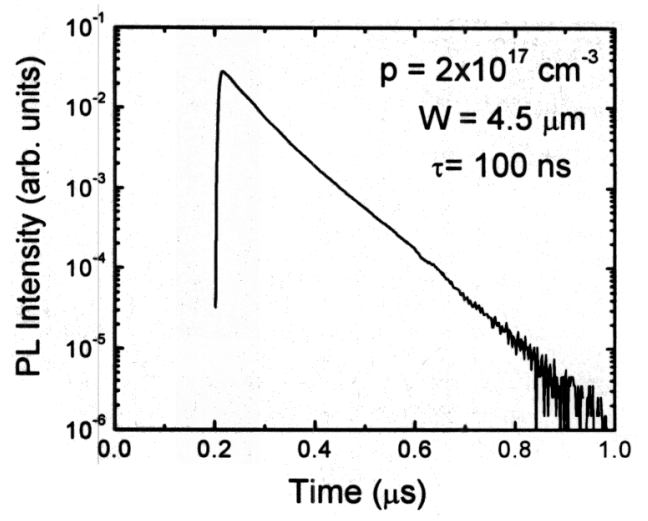

(b)

FIGURE 2. (a) Optical modulation response obtained for $4.5-\mu \mathrm{m}$-thick $0.54 \mathrm{eV} \mathrm{AlGaAsSb} / \mathrm{GaInAsSb} /$ AlGaAsSb DHs with $p=1 \times 10^{16} \mathrm{~cm}^{-3}$ and $p=2 \times 10^{17} \mathrm{~cm}^{-3}$.

(b) Transient PL decay obtained for the structure with $p=2 \times 10^{17} \mathrm{~cm}^{-3}$. 


\section{RESULTS AND DISCUSSION}

Study of the carrier recombination processes was performed on various sets of DHs with varied active layer thickness, bandgap, doping concentration, and different types of confinement layers. Measurement of the hole lifetime was performed for a set of $0.6-\mathrm{eV} \mathrm{GaSb} / \mathrm{GaInAsSb} / \mathrm{GaSb} \mathrm{DHs}$ with active layer thicknesses $(W)$ of $1,1.5$ and $3 \mu \mathrm{m}$ doped with Te at $n=3 \times 10^{17} \mathrm{~cm}^{-3}$. The lifetime data for this set of structures revealed a large interface recombination velocity $S=5 \times 10^{3} \mathrm{~cm} / \mathrm{s}$ determined from the slope of the dependence in Figure $3 \mathrm{a}$ according to the expression

$$
\frac{-}{\tau_{P L}}=\frac{1}{\tau_{b u l k}}+\frac{2 S}{W}
$$

where $\tau_{P L}$ and $\tau_{b u l k}$ are the measured PL decay constant and the bulk lifetime, respectively, and $W$ is the active layer thickness. The large interface recombination velocity was attributed to a low heterobarrier height, which provides minimal carrier confinement and allows thermionic carrier leakage. Rapid decrease of the lifetime with temperature (Figure $3 \mathrm{~b}$ ) also confirms this statement. A bulk hole lifetime of 100 ns was determined from the dependence of $1 / \tau_{P L}$ on $1 / W$ in Figure 3a. Similar bulk lifetime was obtained for electrons in $p$-type structures with similar doping concentration [8]. Therefore, the bulk electron lifetime is consistent with the doping

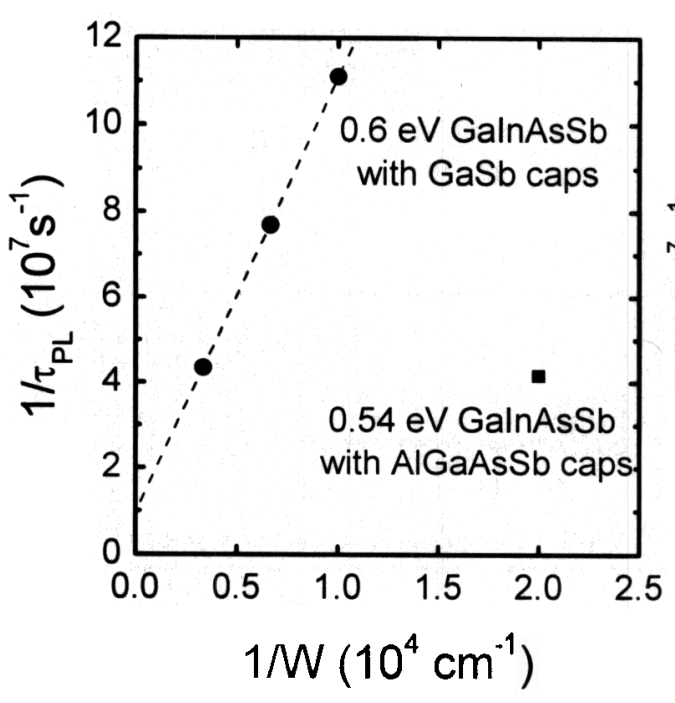

(a)

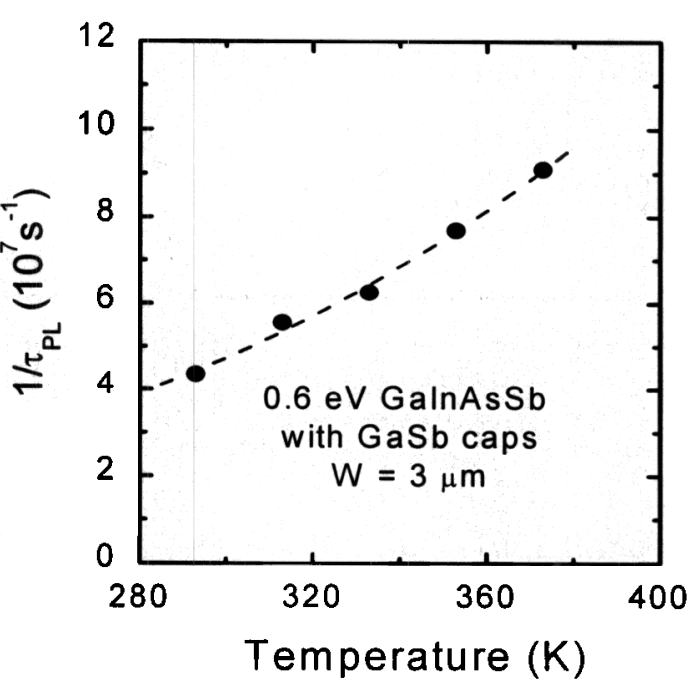

(b)

FIGURE 3. (a) The hole lifetime measured in $0.6 \mathrm{eV}$ GaInAsSb DHs with GaSb caps and 0.54-eV GaInAsSb DH with AlGaAsSb caps. The electron concentration is $n=3 \times 10^{17} \mathrm{~cm}^{-3}$ for all structures.

(b). Temperature dependence of the hole lifetime in a 3- $\mu$ m-thick $0.6-\mathrm{eV}$ GaInAsSb DH with GaSb confinement layers. 
level and indicates good quality of the epitaxial GaInAsSb doped with Te. The hole lifetime in a single $0.54-\mathrm{eV}$ AlGaAsSb/GaInAsSb/ AlGaAsSb DH with an active layer doping $n=3 \times 10^{17} \mathrm{~cm}^{-3}$ and a thickness of $W=0.5 \mu \mathrm{m}$ is shown in Figure $3 \mathrm{a}$ as well. The lifetime, which is similar to the $3-\mu \mathrm{m} \mathrm{GaSb} / \mathrm{GaInAsSb} / \mathrm{GaSb} \mathrm{DH}$ lifetime, suggests that the 1-eV AlGaAsSb cap layers significantly improve minority hole confinement. Additional measurements over range of sample thicknesses would be required to confirm a lower interface recombination velocity. To date there are only limited data on hole lifetime in GaInAsSb materials. Further study would be required for a more complete understanding of how n-type region of $p$-n junction affects the TPV device performance.

Study of the electron lifetime in GaInAsSb materials was performed more extensively since the emitter in a typical TPV device is of $p$-type [1]. GaInAsSb layers with bandgap of 0.5 to $0.55 \mathrm{eV}$ provide more effective absorption of IR radiation from non-wavelength-selective radiators heated at $\sim 1000{ }^{\circ} \mathrm{C}$ compared to $0.6-\mathrm{eV}$ GaInAsSb layers. However, the wider bandgap of $0.6-\mathrm{eV}$ GaInAsSb epitaxial layers have better structural and optical quality compared to structures with the smaller bandgap due to the miscibility gap of GaInAsSb [3]. Composition modulation increases as the bandgap of the material decreases [2]. From that one can expect that the $0.5 \mathrm{eV}$ quaternary should have a shorter lifetime. Measurement of the electron lifetime was performed at room temperature for a set of $\mathrm{GaSb} / \mathrm{GaInAsSb} / \mathrm{GaSb} \mathrm{DHs}$ with active layer bandgap varied in the range from 0.5 to $0.6 \mathrm{eV}$ (Figure 4a). For comparison purposes all data presented in this figure were obtained on samples with the active layer thickness $W=2 \mu \mathrm{m}$. The structures were doped with $\mathrm{Zn}$ to $2 \times 10^{17}$ $\mathrm{cm}^{-3}$ or were undoped with the background doping concentration $p=1 \times 10^{16} \mathrm{~cm}^{-3}$. The GaSb confinement layers were undoped. The shortest decay time was measured for materials with a bandgap close to $0.6 \mathrm{eV}$. The effect of the active layer doping on the lifetime was found to be smaller than the effect of the barrier height for electrons. Thus, we associated rapid decrease of the lifetime in wider bandgap GaInAsSb with a lower conduction band discontinuity. It was assumed that the overall recombination rate is dominated by heterobarrier thermionic emission.

In order to verify this statement, measurements of the temperature dependence of surface recombination velocity $S$ were performed in $0.54-\mathrm{eV} \mathrm{GaSb} / \mathrm{GaInAsSb} /$ $\mathrm{GaSb}$ DHs. The interface recombination velocity was determined in DHs with the active layer doping $p=2 \times 10^{17} \mathrm{~cm}^{-3}$ and thickness in the range from 1.2 to $4 \mu \mathrm{m}$. Two sets of DHs were grown with undoped $\left(p=1 \times 10^{16} \mathrm{~cm}^{-3}\right)$ and doped $\left(p=2 \times 10^{18} \mathrm{~cm}^{-}\right.$ $\left.{ }^{3}\right) \mathrm{GaSb}$ confinement layers. The strong temperature dependence of $S$ observed in DHs with undoped $\mathrm{GaSb}$ layers (Figure $4 \mathrm{~b}$ ) indicated the important role of thermionic electron leakage over the heterobarrier. According to calculations, accumulation of electrons at the type-II interface of 0.54-eV GaInAsSb with undoped GaSb layers can significantly increase the interface recombination rate [8] and contributes to the overall interface recombination velocity. Due to contribution of several processes, quantitative analysis of the temperature dependence of $S$ is not straightforward. Both mechanisms were reduced in DHs with doped GaSb caps by increasing the effective barrier height and reducing the potential well for electrons at the interface resulted in the lower value of $S$. 


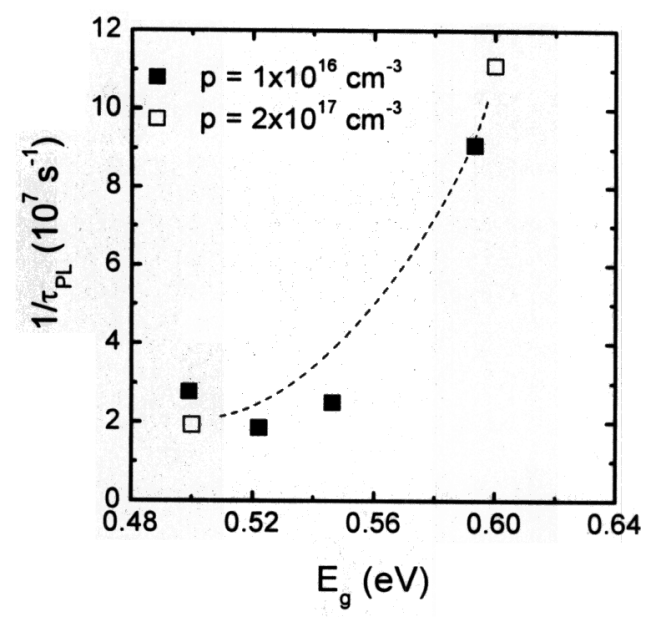

(a)

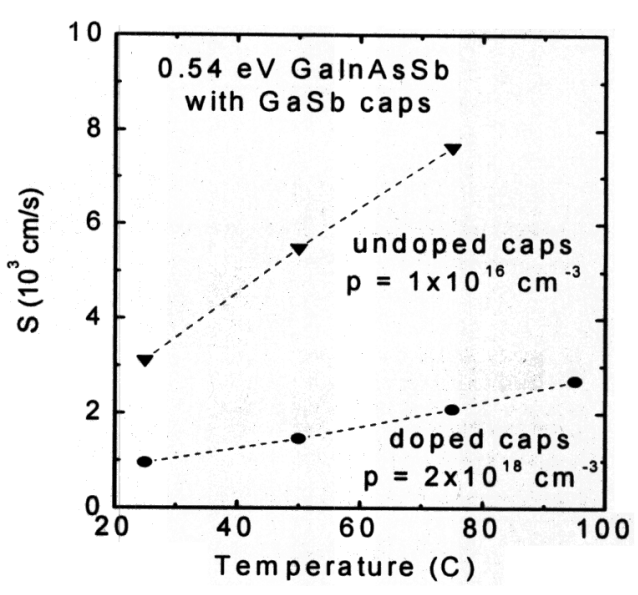

(b)

FIGURE 4. (a) The electron lifetime in GaInAsSb with GaSb confinement layers versus the active layer bandgap

(b) Temperature dependence of recombination velocity at $0.54-\mathrm{eV}$ GaInAsSb/GaSb interface

The electron confinement is further improved in DHs with AlGaAsSb cap layers. The electron lifetime was studied in a set of ten $0.53-\mathrm{eV} \mathrm{AlGaAsSb} / \mathrm{GaInAsSb} /$ AlGaAsSb DHs with active layers doped with $\mathrm{Zn}$ to $2 \times 10^{17} \mathrm{~cm}^{-3}$ and thickness in the range from 0.15 to $4.5 \mu \mathrm{m}$. The $\mathrm{Al}$ composition was selected to minimize the valence band offset between the active and confinement layers. The valence band line up reduces carrier trapping at the heterointerface, while the conduction band offset of $\sim 0.47 \mathrm{eV}$ eliminates thermionic carrier leakage from the active region. The obtained PL decay constants are shown in Figure 5a. Thin DHs are most sensitive to interface recombination and least sensitive to photon reabsorption. Consequently, only DHs with $W<0.5 \mu \mathrm{m}$ were used to determine the interface recombination velocity of 30 $\mathrm{cm} / \mathrm{s}$. Increase of lifetime with active layer thickness for DHs with $W>0.5 \mu \mathrm{m}$ is attributed to a decrease of the contribution of radiative recombination due to the effect of photon reabsorption. This effect is described by the photon recycling coefficient $\phi(W)$ :

$$
\frac{1}{\tau_{b u l k}}=\frac{-}{\tau_{N R}}+\frac{B p}{\phi(W)}
$$

where $\tau_{N R}$ is the non-radiative bulk lifetime, $B$ is the radiative recombination coefficient, and $\mathrm{p}$ is the majority carrier concentration.

In order to extract the radiative coefficient $B$ from the lifetime data, the recycling factor $\phi(W)$ was calculated. The measured fundamental absorption edge for GaInAsSb is shown in Figure 6a. Overlap of the spontaneous emission and absorption spectra illustrates the importance of accounting for photon reabsorption in thick structures. The photon recycling factor for $\mathrm{AlGaAsSb} / \mathrm{GaInAsSb} / \mathrm{AlGaAsSb} \mathrm{DH}$ was calculated using the approach similar to that reported in [10]. The model takes into account reflection from the front surface and assumes complete photon losses at the 
back surface. Figure $6 \mathrm{~b}$ presents the calculated value of $1 / \phi(W)$ versus $1 / W$ that was used to fit the lifetime data to expression (3) using nonradiative bulk lifetime $\tau_{N R}$ and radiative coefficient $B$ as parameters. The best fit was achieved with $\tau_{N R}=180 \mathrm{~ns}$ and $B=1.6 \times 10^{-10} \mathrm{~cm}^{3} / \mathrm{s}$. The radiative lifetime for the structure doped at $p=2 \times 10^{17} \mathrm{~cm}^{-3}$ can be estimated as $30 \times \phi$ ns. The large value of $B$ correlates with the large improvement of lifetime in a wafer-bonded structure with a back surface reflector (BSR) in comparison to the control structure without the BSR [11].

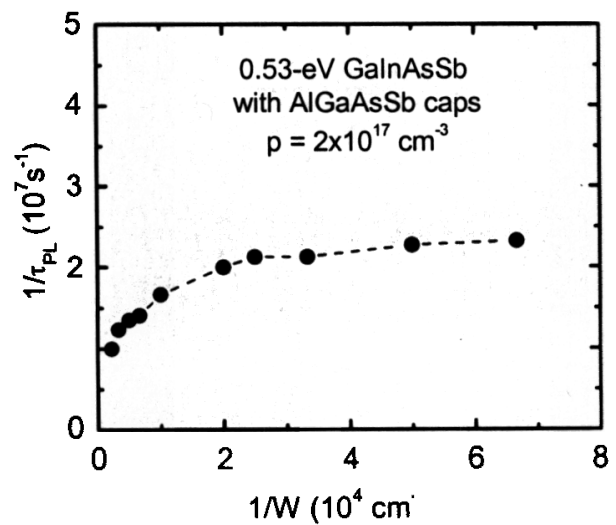

(a)

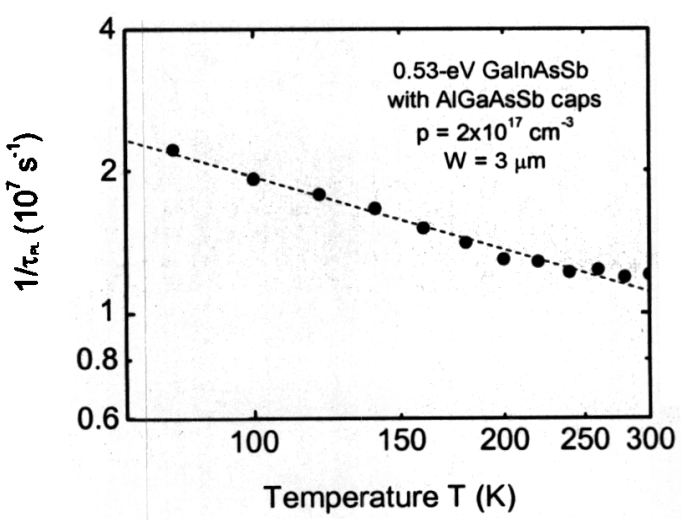

(b)

FIGURE 5. (a) Dependence of the electron lifetime on active layer thickness for $0.53-\mathrm{eV}$ GaInAsSb DHs with AlGaAsSb confinement layers.

(b)Temperature dependence of the electron lifetime for the 3- $\mu$ m-thick $0.53-\mathrm{eV}$ GaInAsSb DH with AlGaAsSb confinement layers.

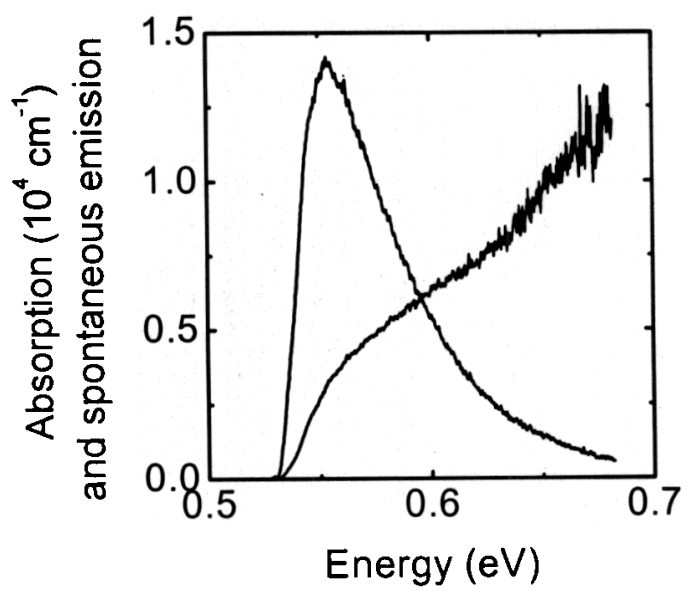

(a)

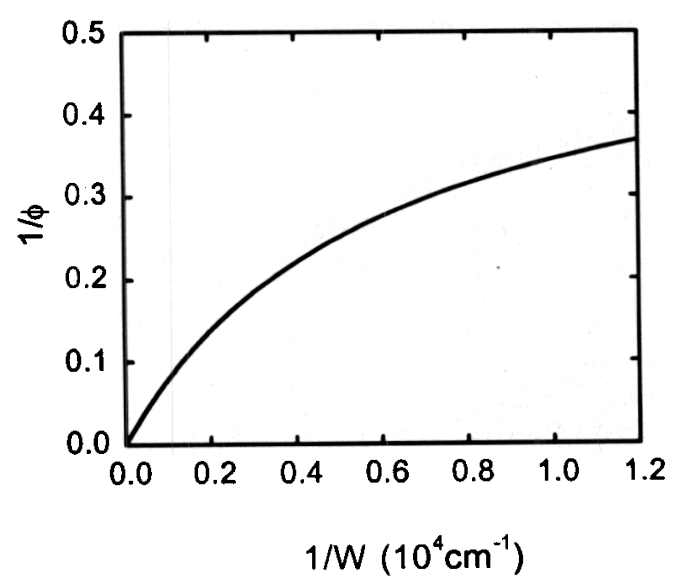

(b)

FIGURE 6. (a) Measured absorption edge spectrum for $0.53-\mathrm{eV}$ GaInAsSb DHs. The spontaneous emission spectrum is shown to illustrate the overlap with the absorption spectrum.

(b) The calculated dependence of the inverse photon recycling on the reciprocal structure thickness 
For non-degenerate bulk materials the probability of radiative recombination is proportional to temperature to the power of $-3 / 2$. Consequently, in structures where radiative recombination dominates, the lifetime should increase with temperature as $T^{3 / 2}$ neglecting the bandgap temperature dependence. Increase of the lifetime with temperature was observed indicating the important role of radiative recombination (Figure 5b). Measured dependence of PL decay time in the range from $T=80$ to 300 $\mathrm{K}$ for the 3- $\mu \mathrm{m}$ thick DH from this set can be approximated as $\tau_{P L} \sim T^{1 / 2}$, indicating the influence of non-radiative recombination. The estimated radiative lifetime of $160 \mathrm{~ns}$ at $T=300 \mathrm{~K}$ for that sample approaches the non-radiative lifetime of $180 \mathrm{~ns}$ determined above.

Demonstration of heterostructures with very low interface recombination suggests that non interface recombination process should limit TPV open-circuit voltage. One complication, however, is the influence of TPV device processing on minority carrier recombination. TRPL was used to characterize processed samples with metal patterns on the top. The excess carrier lifetime was measured in a gridded undoped $\mathrm{DH}\left(p=1 \times 10^{16} \mathrm{~cm}^{-3}\right)$ with an active layer thickness of $0.4 \mu \mathrm{m}$. The structure was processed similarly to the top contact in a TPV device and has a metal contact grid with bus bars and fingers (Figure 7a). We found that processing of this contact grid can reduce the carrier lifetime (Figure $7 \mathrm{~b}$ ) possibly contributing to degradation of device open circuit voltage. Assuming that the measured lifetime change is due to the increase in front surface recombination, one can estimate the upper limit for this increase as $\Delta S=W \Delta(1 / \tau)=600 \mathrm{~cm} / \mathrm{s}$.

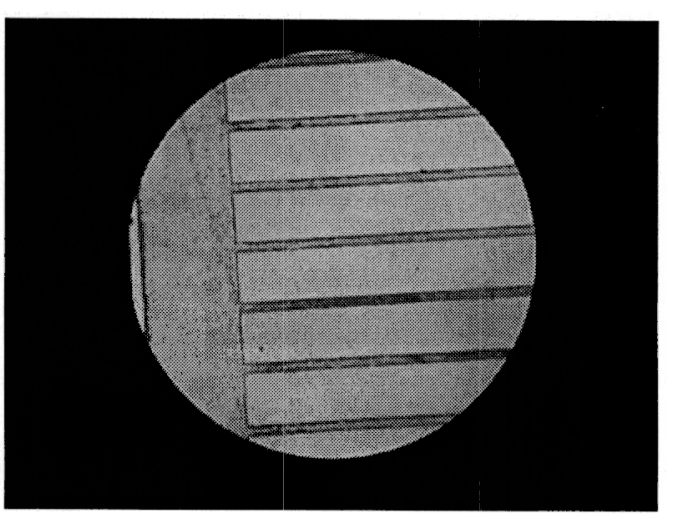

(a)

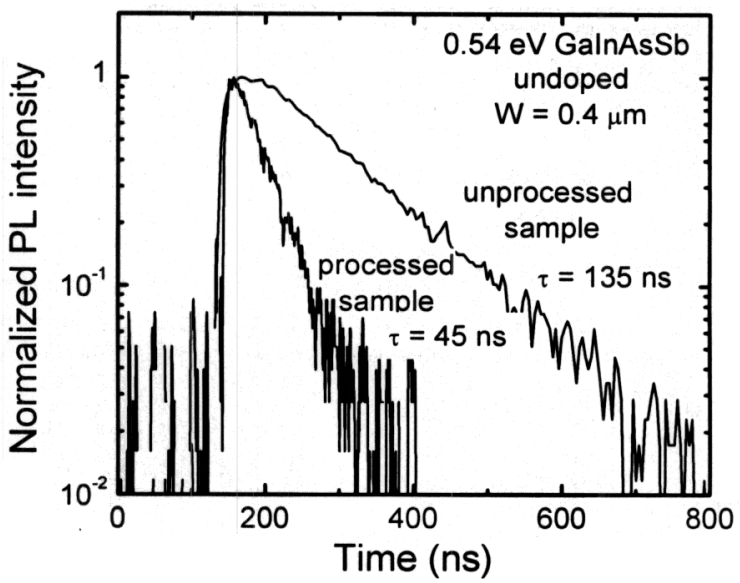

(b)

FIGURE 7. (a) The processed sample with grid contacts

(b) Effect of the grid contact on the electron lifetime in undoped $\left(p=\times 10^{16} \mathrm{~cm}^{-3}\right) 0.54 \mathrm{eV}$ GaInAsSb/AlGaAsSb DH with the active layer thickness of $0.4 \mu \mathrm{m}$. 


\section{CONCLUSIONS}

The importance of the heterobarrier height for minority-carrier lifetime in GaInAsSb structures was shown. An interface recombination velocity as low as $30 \mathrm{~cm} / \mathrm{s}$ was measured in high quality GaInAsSb layers with AlGaAsSb interfaces grown by OMVPE.

It was shown that in doped structures with thickness above $0.5 \mu \mathrm{m}$ and small interface recombination, the effect of photon reabsorption can contribute significantly to the dependence of the lifetime on thickness. This effect can be used to determine both radiative recombination coefficient and a non-radiative bulk lifetime.

\section{REFERENCES}

1. G. W. Charache, P. F. Baldasaro, L. R. Danielson, D. M. DePoy, J. Freeman, C. A. Wang, H. K. Choi, D. Z. Garbuzov, R.U. Martinelli, V. Khalfin, S. Saroop, J.M. Borrego, and R. J. Gutmann, J. Appl. Phys., 85, 2247 (1999).

2. C. A. Wang, C. J. Vineis, H. K. Choi, M. K. Connors, R. K. Huang, L .R. Danielson, G. Nichols, G. W. Charache, D. Donetsky, S. Anikeev, and G. Belenky, AIP Conf. Proc., 653, 324 (2003).

3. C.A. Wang, H.K. Choi, and G.W. Charache, IEE Proc.-Optoelectron., 147, 193 (2000).

4. S. Saroop, J. M. Borrego, R. J. Gutmann, G. W. Charache, C. A. Wang, J. Appl. Phys., 86, 1527 (1999).

5. R. K. Ahrenkiel and S. W. Johnston, Mat. Sci. Eng., B102, 161 (2003).

6. J. Shah, IEEE J. of Quantum Electron., 24, 276 (1988).

7. C. A. Wang, D. A. Shiau, P. G. Murphy, P. W. O'Brien, R. K. Huang, M. K.Connors, A. C. Anderson, D. Donetsky, S. Anikeev, G. Belenky, D. M. Depoy, and G. Nichols, J. Electron. Mater., 33, 213 (2004).

8. D. Donetsky, S. Anikeev, G. Belenky, S. Luryi, C. A. Wang, and G. Nichols, Appl. Phys. Lett., 81, 4769 (2002).

9. S. Anikeev, D. Donetsky, G. Belenky, S. Luryi, C. A. Wang, J. M. Borrego, and G. Nichols, Appl. Phys. Lett., 83, 3317 (2003).

10. P. Asbeck, J. Appl. Phys., 48, 820 (1977).

11. C. A. Wang, D. A. Shiau, P.G. Murphy, P. W. O'Brien, R. K. Huang, M. K. Connors, A. C. Anderson, D. Donetsky, S. Anikeev, G. Belenky, D. M. Depoy, G. Nichols, J. Electron. Mater., 33, 213 (2004) 